\title{
Economía y biología. La decisiva influencia del naturalismo en la construcción teórica de la Economía Política
}

\author{
Economy and biology. The decisive influence of naturalism in \\ the theoretical construction of the Political Economy
}

JORGE POLO BLANCO*

\begin{abstract}
Resumen: En el presente trabajo queremos esbozar un recorrido crítico en torno a un problema que, como tantos otros, atraviesa las fronteras de la filosofía y la ciencia social. Se trata de comprobar la notable influencia ejercida por algunos elementos naturalistas en la construcción misma de una disciplina que, a la postre, resultó tener una importancia crucial. En efecto, sostendremos que el nacimiento de la Economía Política estuvo marcado, en su constitución misma como disciplina, por una serie de retroalimentaciones teóricas e ideológicas con otros campos del saber más vinculados a la ciencia natural y en especial con todos los saberes que fueron tejiéndose en torno a la biología evolutiva. Creemos de sumo interés la indagación en estos procesos de construcción teórica, toda vez que hablamos de una disciplina que siempre mantuvo una relevancia esencial en la provisión de interpretaciones hegemónicas del orden social.

Palabras clave: economía política, naturalismo, biologización del orden social, darwinismo social.
\end{abstract}

\begin{abstract}
In the present work we aim to outline a critical exploration centred on a problem that, like so many others, extends across the borders of philosophy and social science. It involves the corroboration of the notable influence exercised by certain naturalist elements in the construction of a discipline that was, ultimately, of key importance. To this effect, we maintain that the birth of the Political Economy was defined, in its establishment as a discipline, by theoretical and ideological feedback with other fields of knowledge that have closer links to natural science and, particularly, to all knowledge interwoven around evolutionary biology. We feel that the investigation into these processes of theoretical construction is of the upmost importance, provided we are talking about a discipline that always maintained a vital relevance to the provision of hegemonic interpretations of the social order.

Keywords: political economy, naturalism, biologization of the social order, social Darwinism.
\end{abstract}

Fecha de recepción: 30/01/2015. Fecha de aceptación: 29/06/2015.

* Universidad Técnica del Norte, Ecuador (jpolo@utn.edu.ec). Es Doctor en Filosofía por la Universidad Complutense de Madrid. Es autor de La economía tiránica. Sociedad mercantilizada, dictadura financiera y soberanía popular, Madrid, Carpe Noctem, 2015. Ha publicado varios artículos académicos siguiendo diversas líneas de investigación, vinculadas a la filosofía política moderna y al ámbito de las ciencias sociales: "Posdemocracia y dictadura tecnofinanciera. La tiranía de los mercados omnipotentes", Nómadas. Revista crítica de ciencias sociales y jurídicas, Universidad Complutense de Madrid, Vol. 44, No 4, 2014, pp. 145162. "También explotación, pero no sólo. Un diálogo imprescindible y polémico entre Marx y Karl Polanyi", Tópicos. Revista de Filosofía, Universidad Panamericana, México, No 49, 2015, pp. 81-121. También publicó el libro Perfiles posmodernos. Algunas derivas del pensamiento contemporáneo, Madrid, Dykindon, 2010. 


\section{Leyes económicas emancipadas}

Poco antes de alcanzar los umbrales del siglo XIX, en 1797, Thomas Paine anotaba en la primera página de su Agrarian Justice que el observador de la civilización moderna quedaba atónito y estupefacto ante un espectáculo que ofrecía, en un mismo movimiento, todo el oropel de la gran riqueza acumulada por los propietarios y la miseria más sórdida de los desposeídos ${ }^{1}$. La preocupación por la pobreza no natural, esto es, por la pobreza social generada en el despliegue mismo del nuevo orden económico, suscitaba los primeros acercamientos sistemáticos (teóricos y políticos) a este singular y decisivo fenómeno. El descubrimiento científico de lo social, la tremenda realidad del pauperismo y el nacimiento de la economía política como disciplina son distintos acontecimientos que emergen no obstante entrelazados y acompasados.

El origen del pauperismo, como bien supo señalar Karl Polanyi, resultaba especialmente desconcertante para los nuevos pensadores decimonónicos de lo social, y descifrar de una manera convincente su etiología resultaba un enigma considerable para una época caracterizada por el incremento portentoso de la riqueza global de las naciones y por el aumento exponencial de la capacidad productiva. "La pobreza era la naturaleza que sobrevivía en la sociedad; la ironía sólo se volvía más amarga por el hecho de que la limitación de los alimentos y el carácter ilimitado de los hombres se enfrentaban justo cuando la promesa de un incremento sin límites de la riqueza llegaba hasta nosotros"2. Ya a lo largo del siglo XVIII empiezan a asomar las primeras consideraciones generales y sistemáticas sobre el origen de la riqueza social, pero integrar la miseria en ese cuadro resultaba todavía muy problemático. "Ni la nueva riqueza ni la nueva pobreza eran todavía enteramente comprensibles"3. La importancia crucial de la pobreza como elemento clave a través del cual descubrir los íntimos y secretos resortes del funcionamiento social empieza a cobrar visibilidad manifiesta cuando el siglo XIX asoma su inédito rostro de una manera plena, esto es, cuando los fuegos de la industria capitalista avanzan ya con paso firme y contundente.

Las mismas leyes económicas que incrementaban la riqueza de las naciones hasta niveles jamás vistos eran, al mismo tiempo, las responsables de inhumanos niveles de explotación y desintegración cultural para enormes masas humanas. La constatación de este fenómeno brutalmente paradójico atravesaría y tensionaría en muchas direcciones todo el pensamiento social decimonónico. "El pauperismo, la economía política y el descubrimiento de la sociedad se entrelazaban estrechamente. El pauperismo centraba la atención en el hecho incomprensible de que la pobreza parecía ir de la mano de la abundancia. Pero ésta era sólo la primera de las intrigantes paradojas que la sociedad industrial habría de plantear al hombre moderno, quien había entrado a su mundo por la puerta de la economía [...] Las leyes del mercado significaban para ellos el límite de las posibilidades humanas"4. La nueva representación de lo social se había fraguado a través de la constitución de una esfera económica cada vez más independizada que había ido escindiéndose y desgajándose de la urdimbre societaria. Esa mutación decisiva, y esto Polanyi lo estudió muy bien, implicó una revolución

1 Paine, T., El sentido común y otros escritos, Madrid, Tecnos, 1990, p. 101.

2 Polanyi, K., La gran transformación, México, Fondo de Cultura Económica, 2003, p. 136.

3 Ibíd., p. 163.

4 Ibíd., p. 136. 
institucional sin precedentes. Suponía, antes que nada, una nueva inserción antropológica en la matriz de las leyes del mercado En efecto, el sistema de mercado, que aparecía como una novedad absoluta desde todo punto de vista etnográfico e histórico, configuró un orden social dentro del cual la legalidad de la esfera económica se desplegaba en una dinámica cada vez más autónoma con respecto a las demás esferas y normas sociales 5 . Dichas leyes, que además aparecían representadas bajo la égida de lo ineluctable, tenían el efecto de situar a los hombres en un nuevo marco renaturalizado, como ahora iremos viendo.

Polanyi se detuvo en esta problemática, y comenzó haciendo un importante matiz. Adam Smith no pertenecía todavía a las nuevas perspectivas que sólo desplegarían su potencial con el desarrollo de la nueva centuria decimonónica. "La división ocurrió alrededor de 1780. En la gran obra de Adam Smith, el auxilio de los pobres no constituía todavía ningún problema; sólo un decenio más tarde, se planteó como un problema general en la Dissertation on the Poor Laws de Townsend y nunca dejó de ocupar la mente de los hombres durante los siguientes 150 años [...] El cambio de atmósfera, de Adam Smith a Townsend, fue en efecto sorprendente. El primero marcó el final de una época que se abrió con los inventores del Estado: Tomás Moro y Maquiavelo, Lutero y Calvino; el último pertenecía a ese siglo XIX en el que Ricardo y Hegel descubrieron desde ángulos opuestos la existencia de una sociedad que no estaba sujeta a las leyes del Estado sino que, por el contrario, sometía al Estado a sus propias leyes. Es cierto que Adam Smith trató la riqueza material como un campo de estudio separado; el hecho de que lo lograra con un gran sentido del realismo lo convirtió en el fundador de una nueva ciencia: la economía. Pero la riqueza era para él sólo un aspecto de la vida de la comunidad, a cuyos propósitos permanecía subordinada; era una característica de las naciones que luchan por su supervivencia en la historia y no podía separarse de ellas" 6 . En ese sentido, si bien es verdad que Polanyi consigna que en la obra de Smith la constitución de una esfera económica separada ya empieza a ser una realidad relativamente desarrollada, hasta el punto de que una disciplina científica específica puede germinar en torno a ella, reconoce sin embargo que en la obra del pensador escocés la "vida económica" aún permanece integrada en el destino común de la nación, sin independizarse plenamente en un mecanismo institucional autónomo, omnipotente y tiránico.

En efecto, en el pensamiento de Smith de ningún modo la vida económica se articula en una esfera funcionalmente separada de los restantes elementos de la vida social. "No hay en su obra ninguna sugerencia de que los intereses económicos de los capitalistas impusieran su ley a la sociedad, de que tales intereses fueran los voceros seculares de la divina providencia que gobernara al mundo económico como una entidad separada. Con Adam Smith, la esfera económica no está todavía sujeta a sus propias leyes que provean de un patrón de lo bueno y lo malo"7. La esfera de la producción de riqueza era considerada por Smith como una función de la vida física y moral de la nación, y en ese sentido era todavía una función subordinada o, al menos, no del todo desligada. "En su opinión, nada indica la presencia de una esfera económica en la sociedad que pudiera convertirse

\footnotetext{
5 Ibíd., p. 121.

6 Ibíd., p. 165.

7 Ibíd.
} 
en la fuente de la ley moral y la obligación política"». La legalidad económica no era pensada como una estructura autónoma a la que toda forma política y moral hubiera de estar inexorablemente sometida.

Por otro lado observa Polanyi que Adam Smith excluyó conscientemente a la naturaleza, en un sentido puramente biológico, del problema de la riqueza. Cualesquiera que sean el suelo, el clima o la extensión orográfica y territorial de una nación particular dada, la abundancia o escasez de su abasto anual dependerá de dos factores: la habilidad de los trabajadores y la proporción existente entre estos últimos y los miembros ociosos de la población. En cualquier caso hablamos siempre de factores de orden político. "Sólo intervienen los factores humanos, no los naturales. Esta exclusión del factor biológico y geográfico, al inicio mismo de su libro, fue deliberada. Las falacias de los fisiócratas le sirvieron de advertencia; su predilección por la agricultura los llevaba a confundir la naturaleza física con la naturaleza humana, y no los inducía a sostener que sólo el suelo era verdaderamente creativo. Nada estaba más lejos de Smith que tal glorificación de la Physis"9. El naturalismo todavía no se había deslizado hacia el interior mismo del pensamiento social, como habría de ocurrir muy poco después. Y esta diferencia será crucial.

\section{Biologización de las leyes económicas, animalización del orden social}

Polanyi localizó muy certeramente un trascendental y decisivo punto de inflexión en la deriva constructiva de la economía política. Joseph Townsend, médico y geólogo, publicaba su Dissertation en 1786, justo cuando había transcurrido una década desde la aparición de la gran obra de Smith. En este texto se habría de incluir el llamado "teorema de las cabras y los perros". Al parecer, en la isla de Robinson Crusoe, frente a las costas de Chile, Juan Fernández dejó unas cuantas cabras para proveerse de carne en futuras visitas. Las cabras allí desembarcadas, que se multiplicaron exponencialmente, acabaron sirviendo de alimento a los corsarios que estaban obstruyendo el comercio de los españoles, los cuales, con el fin de destruirlas, dejaron perros en la isla, y la población de estos últimos también aumentó hasta cierto límite. Se estableció un nuevo balance dentro del conjunto biótico, aseguraba Townsend, un nuevo y espontáneo equilibrio poblacional. "La más débil de ambas especies fue la que primero pagó su deuda con la naturaleza; la más activa y vigorosa preservó la vida"10. Y, ulteriormente, aplicaría este mismo esquema al interior de los grupos estrictamente antropológicos. "Es la cantidad de alimentos lo que regula el número de la especie humana"11. Como podemos comprobar en estas sentencias de Townsend, citadas por el propio Polanyi, se ha producido ya un importante salto desde lo animal a lo humano, con todas las decisivas mutaciones que ello conlleva. Semejante operación discursiva será crucial para las conceptualizaciones trazadas por la economía política y por la teoría social en general.

¿Qué deslizamiento teórico se produce en el tránsito que media entre Smith y Townsend? Más allá del anecdótico relato, cuya autenticidad es puesta en duda por Polanyi, lo importante es tener en cuenta el recurso explicativo que Towsend pone en juego a la hora de dar

8 Ibíd., p. 166.

9 Ibíd.

10 Ibíd., p. 167.

11 Ibíd. 
cuenta de las causas que determinan la pobreza y la riqueza de las sociedades humanas. En efecto, estamos hablando de factores enteramente análogos a los que determinan el equilibrio de un ecosistema estrictamente zoológico. Una explicación puramente ecológica se infiltra en el interior de las construcciones teóricas que dan cuenta de la realidad social, y el naturalismo va permeando y penetrando la médula de la naciente economía política. Los imperativos propios de la desnuda vida biológica empiezan a ocupar una posición cada vez más hegemónica en el interior de las consideraciones y conceptualizaciones del orden social ${ }^{12}$.

Polanyi, en efecto, y pese a constatar la escasa credibilidad de los hechos narrados en torno a la isla mencionada, como indicábamos hace un momento, asevera lo siguiente: "Pero el paradigma no depende del apoyo empírico. La carencia de una autenticidad de anticuario no puede restar nada al hecho de que Malthus y Darwin debieron su inspiración a esta fuente: Malthus la aprendió de Condorcet, Darwin de Malthus. Pero ni la teoría de la selección natural de Darwin, ni las leyes de la población de Malthus, podrían haber ejercido ninguna influencia apreciable sobre la sociedad moderna de no haber mediado las máximas siguientes que Townsend dedujo de sus cabras y sus perros y que deseaba aplicar a la Ley de Pobres:[...]"13. Ese nuevo paradigma, en efecto, obtendrá vigor y recorrido en las concepciones decimonónicas de la economía política, como iremos viendo a continuación.

Polanyi no puede resistir la tentación de citar otro brutal y explícito fragmento de la Dissertation on the Poor Laws en la cual Townsend elabora esa crucial simbiosis entre factores políticos y biológicos a la hora de dar cuenta de la realidad social. El texto es elocuente y descarnado: "El hambre domará a los animales más feroces, les enseñará decencia y civilidad, obediencia y sujeción, al más perverso. En general, es sólo el hambre lo que puede aguijonearlos y moverlos [a los pobres] a trabajar; pero nuestras leyes han dicho que los pobres no tendrán hambre jamás. Debemos confesar que las leyes han dicho también que los pobres serán obligados a trabajar. Pero entonces la restricción legal se atiende con grandes problemas, violencias y ruidos; crea mala voluntad y nunca puede producir un servicio bueno y aceptable; en cambio, el hambre no es sólo pacífica, silenciosa, una presión constante, sino que, como la motivación más natural para la industria y el trabajo, induce los esfuerzos más poderosos" 14 . Algo tan desnudamente biológico como el hambre habría de ser, a juicio de Townsend, el acicate que movilizara a los hombres y determinara en última instancia los derroteros de la ordenación social. Las Leyes de Pobres eran sólo un artefacto inútil que interfería en aquello que el hambre, dejada a su libre imperar, podría erigir por sí sola. Ella establecería las pautas del orden social, ella determinaría la legalidad del mundo del trabajo, ella establecería el balance final de los que habrían de prosperar o perecer.

Pero hemos de tener en cuenta que estas proposiciones normativas que encontramos en algunos discursos hubieron de realizarse en buena medida. En efecto, la implantación de una legalidad capitalista desatada y sin cortapisas acabó por configurar un espacio cuasi-animalizado para las clases populares. Robert Castel, al describir la situación de los asalariados en la naciente sociedad industrial, y tras consignar la exaltada descripción liberal del ideal contractual por el cual dos partes formalmente libres llegan a un muto acuerdo, descubre

12 Esposito, R., "Vida biológica y vida política", Pléyade, No 12, Julio-Diciembre 2013, pp. 15-33.

13 Polanyi, K., La gran transformación, México, p. 167.

14 Ibíd. 
empero a un trabajador cuya situación existencial se desliza hasta los lindes mismos de la mera existencia animal. El contrato capitalista, que venía a sustituir las ligazones gremiales, abría una perspectiva radicalmente distinta para los vendedores de fuerza de trabajo. "Al abolir las protecciones tradicionales, se corría el riesgo de hacer aflorar, no la racionalidad de las leyes naturales, sino la potencia biológica de los instintos; los carecientes se verían entonces impulsados por la necesidad natural, es decir por el hambre. En el segundo plano de la reciprocidad jurídica del contrato de trabajo se perfilaba así la alteridad fundamental de las posiciones sociales de los contratantes y, si en el contrato de trabajo se introducía la dimensión temporal, el espacio pacificado de las relaciones de mercado se transmutaba en un campo de batalla por la vida" 15 . En este esclarecedor pasaje queda muy bien perfilada esa naturalización de la vida social humana impuesta por la tiranía de unas relaciones fraguadas en un mercado de fuerza de trabajo radicalmente desprotegido y desrregulado, tal como era el mercado laboral en las primeras décadas del siglo que nos ocupa.

Ya el joven Marx supo ver en el trabajador insertado en las prácticas laborales capitalistas la terrible reducción a la que estaba siendo sometido, una reducción que lo sumergía ferozmente en la condición bestial y en la animalidad. En los manuscritos de 1844, cuando habla de los ejércitos industriales de trabajadores explotados, Marx mencionaba una motivación que, en efecto, era puramente animal; mujeres y hombres absolutamente despojados de toda posibilidad de reproducir sus condiciones materiales de vida de una manera autónoma e independiente no tenían ya nada más que su propio pellejo, un pellejo que habían de vender al precio que el capital determinara comprarlo, y ello sin otro horizonte que el de no perecer de hambre al día siguiente. "Para ser conducida con éxito, la guerra industrial exige ejércitos numerosos que pueda acumular en un mismo punto y diezmar generosamente. Y ni por devoción ni por obligación soportan los soldados de este ejército las fatigas que se les impone; sólo por escapar a la dura necesidad del hambre. No tienen ni fidelidad ni gratitud para con sus jefes; estos no están unidos con sus subordinados por ningún sentimiento de benevolencia; no los conocen como hombres, sino como instrumentos de la producción que deben aportar lo más posible y costar lo menos posible. Estas masas de obreros, cada vez más apremiadas, ni siquiera tienen la tranquilidad de estar siempre empleadas; la industria que las ha convocado sólo las hace vivir cuando las necesita, y tan pronto como puede pasarse sin ellas las abandona sin el menor remordimiento; y los trabajadores están obligados a ofrecer su persona y su fuerza por el precio que quiera concedérseles"16. Marx hablaba de hombres reducidos a la más animalizada de las existencias, en tanto que el fundamento mismo de su subsistencia y reproducción social material estaba enteramente determinado en último término por un mecanismo ciego y brutal que, al entrar en un determinado ciclo en el que la industria tuviera que prescindir de buena parte del ejército trabajador, podría resultar ser un mecanismo institucional más devastador que una sequía o una plaga para una especie animal cualquiera.

El orden social, en sus mismos fundamentos y resortes, quedaba de esta manera enteramente animalizado para las mayorías sociales explotadas. Y, de manera acompasada, la teorización social iba destilando componentes crecientemente naturalistas. "Aquí estaba

15 Castel, R., Las metamorfosis de la cuestión social, Buenos Aires, Paidós, 1997, p. 207.

16 Marx, K., Manuscritos de economía y filosofía, Madrid, Alianza, 2010, p. 67. 
un nuevo punto de partida para la politología. Al enfocar la comunidad humana desde el lado animal, Townsend omitió la cuestión supuestamente inevitable de los fundamentos del gobierno; y al hacerlo así introdujo un nuevo concepto de la ley en los asuntos humanos, el de las leyes de la naturaleza. El sesgo geométrico de Hobbes, así como la búsqueda ansiosa de las leyes newtonianas en la sociedad por parte de Hume y Hartley, Quesnay y Helvecio, habían sido puramente metafóricos: estaban en ascuas por descubrir una ley tan universal en la sociedad como la gravitación lo era en la naturaleza, pero la consideraban una ley humana, una fuerza mental como el temor en el caso de Hobbes, la asociación en la psicología de Hartley, el interés propio en el caso de Quesnay, o la búsqueda de la utilidad en el caso de Helvecio [...] Aristóteles había enseñado que sólo los dioses o las bestias podrían vivir fuera de la sociedad, y el hombre no era ninguna de las dos cosas. Para el pensamiento cristiano, también el abismo existente entre el hombre y la bestia era constitutivo; ninguna excursión al campo de los hechos fisiológicos podría confundir a la teología acerca de las raíces espirituales de la mancomunidad humana [...] Pero en la isla de Juan Fernández no había gobierno ni ley; y sin embargo había un balance entre cabras y perros. Ese balance se mantuvo por la dificultad encontrada por los perros para devorar a las cabras que huían a la parte rocosa de la isla, y por las inconveniencias que debían afrontar las cabras al buscar un refugio contra los perros. No se necesitaba ningún gobierno para mantener ese balance, el que se restableció por los dolores del hambre por una parte y por la escasez de alimentos por otra. Hobbes había sostenido la necesidad de un déspota porque los hombres son como bestias; Townsend insistió en que los hombres son efectivamente bestias, y que preciosamente por esa razón sólo se requiere un mínimo de gobierno. Desde este punto de vista novedoso, una sociedad libre podía considerarse integrada por dos razas: la de los propietarios y la de los trabajadores. El número de estos últimos estaba limitado por la cantidad de alimentos; y mientras que la propiedad estuviese segura, el hambre los impulsaría a trabajar. No había necesidad de magistrados, ya que el hambre era más disciplinante que los magistrados"17. Hemos creído necesario intercalar esta larga cita de La gran transformación porque en ella Polanyi exponía de una manera muy plástica y certera el núcleo esencial del acontecimiento teórico e ideológico que aquí estamos tratando de analizar.

\section{Una retroalimentación categorial y disciplinar}

Sin duda alguna podríamos afirmar que ya en el mismo Darwin encontramos evidentes tendencias hacia una equiparación u homologación del campo zoológico y del campo antropológico ${ }^{18}$. La comprensión biocenótica del comportamiento humano adquiere su plena y explícita cristalización en la etología clásica. No podemos ahora entrar en ello, pero Tinbergen, uno de los pioneros de la escuela etológica, afirmaba explícitamente que la utilización de una semántica zoológica para una mejor comprensión de nosotros mismos aparecía como un camino extremadamente fructífero ${ }^{19}$. Y algunos autores, en nuestra contemporaneidad, han podido concebir que el derecho y la política ya no pueden entenderse como principios

17 Polanyi, K., La gran transformación, p. 168.

18 Darwin, C., El origen del hombre y la selección en relación al sexo, Madrid, Ediciones Ibéricas, 1966, p. 98.

19 Tinbergen, N., Hombre y animal. Estudios sobre comportamiento, Madrid, Hermann Blume, 1975, p. 119. 
fundantes de algo que nos diferencia, en algún sentido sustancial, del mundo animal ${ }^{20}$. Lo que todas estas concepciones ponen en juego es un doble movimiento que trata de antropomorfizar la conducta animal para ulteriormente animalizar la conducta humana. "La humanización integral del animal coincide con una animalización integral del hombre"21. Esa es la dialéctica que opera en las teorías sociobiológicas ${ }^{22}$.

Marshall Sahlins, en 1976, en su obra The Use and Abuse of Biology. An Anthropological Critique of Sociobiology, intentaría esbozar una reconstrucción del devenir de esa imbricación ideológica que las ciencias biológicas han mantenido, desde el siglo XIX, con la imagen del mundo auspiciada por la sociedad capitalista competitiva y con la imagen del hombre asimismo propugnada por la ciencia económica. "El concepto darwiniano de la selección natural ha sufrido un serio descarrilamiento ideológico en los últimos años" ${ }^{23}$. En efecto, las categorías de la ciencia económica y de las ciencias biológicas entran en una dinámica de retroalimentación mutua. "Se podría decir que el darwinismo, en un principio adaptado a la sociedad como «darwinismo social», ha regresado a la biología como capitalismo genético" 24 . En un proceso que es de doble dirección se produce una traslación de imágenes biológicas a la descripción de las sociedades humanas, a la vez que se da una transferencia de metáforas económicas utilitaristas al reino animal ${ }^{25}$. Se desarrolla, en efecto, una deriva de penetración recíproca entre los elementos del imaginario mercantil y algunos esquemas explicativos de la teoría biológica ${ }^{26}$.

Sahlins postula que tal proceso de interpenetración se ha venido decantando históricamente a lo largo del desarrollo de la moderna sociedad capitalista, hasta concluir en la sociobiología del siglo XX. "Descubrir los rasgos de la sociedad en general en los conceptos de su biología no es del todo una «síntesis moderna». En la sociedad euroamericana esta integración se ha realizado de una determinada forma dialéctica desde el siglo XVII. Por lo menos desde Hobbes, las características competitivas y lucrativas del hombre occidental han sido confundidas con la naturaleza, y la naturaleza, forjada de este modo a imagen del hombre, ha sido a su vez reaplicada a la explicación del hombre occidental. El efecto de esta dialéctica ha sido afianzar las propiedades de la acción social humana, tal y como las concebimos, en la naturaleza, y las leyes de la naturaleza en nuestras concepciones de la acción social humana. La sociedad humana es natural, y las sociedades son curiosamente humanas. Adam Smith proporcionó una versión social de Thomas Hobbes; Charles Darwin una versión naturalizada de Adam Smith; William Graham Summer [darwinista social] reinventa acto seguido a Darwin como sociedad y Edward O. Wilson reinventa a Summer como naturaleza. Desde Darwin se ha acelerado el movimiento de péndulo conceptual"27. Ese trasvase categorial pendular ha producido, en efecto, una naturalización de los resortes

20 Castrodeza, C., La darwinización del mundo, Barcelona, Herder, 2009, p. 286.

21 Agamben, G., Lo abierto. El hombre y el animal, Valencia, Pre-textos, 2005, p. 99.

22 Wilson, E. O., Sociobiología. La nueva síntesis, Barcelona, Omega, 1980.

23 Sahlins, M., Uso y abuso de la biología, Madrid, Siglo Veintiuno, 1982, p. 97.

24 Ibíd.. p. 98.

25 Soutullo, D.; Biología, cultura y ética, Madrid, Talasa, 2005, p. 47.

26 Muñoz Rubio, J., "Biología y economía política: acerca del carácter interdisciplinario de la teoría de Darwin", en La interdisciplina y las grandes teorías del mundo moderno, Univesidad Nacional Autónoma de México, 2007.

27 Sahlins, M., Uso y abuso de la biología, p. 123. 
que vertebran la sociedad competitiva de mercado y, en la otra dirección, una imagen del mundo orgánico-animal construida a imagen y semejanza del modo de funcionamiento propio de una economía de tipo capitalista. "Parece que somos incapaces de escapar a este movimiento perpetuo hacia atrás y hacia delante, entre la culturización de la naturaleza y la naturalización de la cultura, que frustra al mismo tiempo nuestra comprensión de la sociedad y del mundo orgánico”28. Este movimiento pendular resultó determinante en la construcción de algunos presupuestos de la economía política.

Tal dialéctica ideológica ha venido funcionando insidiosamente al compás mismo del desarrollo de la sociedad capitalista y ha configurado en buena medida el desarrollo de la economía política como disciplina. "Desde el siglo XVII parece que nos hemos visto atrapados en ese círculo vicioso, aplicando alternativamente el modelo de la sociedad capitalista al reino animal y luego reaplicando este reino animal aburguesado a la interpretación de la sociedad humana" 29 . En ese juego de traslaciones categoriales se produce una relación equívoca, pues las metáforas se exportan de un ámbito a otro hasta un punto en el que ya no es posible distinguir la referencia original de la derivada. Las explicaciones sociales y económicas aparecen preñadas de imágenes tomadas de lo biológico y, a su vez, las explicaciones biológicas se ven atravesadas de imágenes provenientes de la ciencia económica.

Pues bien, este proceso descrito por Marshall Sahlins, por el cual, y de la mano de la economía política, la naturaleza fue cobrando cada vez más presencia en la comprensión de los asuntos humanos, fue ya detectado en toda su magnitud por Karl Polanyi, como ya veníamos anunciando. “[...] la solución obtenida por los economistas clásicos tuvo consecuencias de muy largo alcance para el entendimiento de la naturaleza de la sociedad económica. A medida que se aprehendían gradualmente las leyes gobernantes de una economía de mercado, estas leyes se ponían bajo la autoridad de la naturaleza misma. La ley de los rendimientos decrecientes era una ley de la fisiología vegetal. La ley malthusiana de la población reflejaba la relación existente entre la fecundidad del hombre y la del suelo. En ambos casos actuaban las fuerzas de la naturaleza, el instinto animal del sexo y el crecimiento de la vegetación en un suelo dado. El principio involucrado era el mismo que en el caso de las cabras y los perros de Townsend: había un límite natural, más allá del cual no podían multiplicarse los seres humanos, y tal límite era fijado por la oferta alimenticia disponible. Al igual que Townsend, Malthus concluyó que los especímenes superfluos serían destruidos; mientras que las cabras son muertas por los perros, éstos deben morir por falta de alimento. En el caso de Malthus, el freno represivo consistía en la destrucción de los especímenes excedentes por las fuerzas brutas de la naturaleza" ${ }^{30}$. Los seres humanos, así animalizados, se mueven en unos parámetros determinados únicamente por límites naturales, variables ecológicas y motivaciones biológicas. "En esencia, la sociedad económica se fundaba en las duras realidades de la naturaleza; si el hombre desobedecía las leyes que regían a esa sociedad, el verdugo acabaría con la descendencia del imprudente. Las leyes de una sociedad competitiva quedaban bajo la sanción de la selva"31. La sociedad capitalista y la economía política por ella generada y excogitada devuelven a los hombres al estado de naturaleza; las

28 Ibíd., p. 137.

29 Ibíd., p. 132.

30 Polanyi, K., La gran transformación, p. 179.

31 Ibíd., p. 180. 
leyes del mercado competitivo, sobrevenidas con la inexorabilidad de las leyes naturales, sitúan de nuevo a las comunidades humanas en el nicho ecológico de la pura supervivencia biológica; y la comunidad política, por lo tanto, se disuelve de nuevo en la pura especie que evoluciona a través de la pugna fisiológica. Los hombres empiezan a ser comprendidos y tratados como homínidos que compiten en la descarnada lucha por la existencia.

La pura supervivencia biológica y el miedo a la inanición son los nuevos móviles y las nuevas fuerzas que regulaban el equilibrio social. “¿Cuál ley ordenaba al trabajador obedecer a un amo, a quien no estaba atado por ningún lazo legal? ¿Cuál fuerza mantenía separadas a las clases de la sociedad, como si fueran clases de seres humanos diferentes? ¿Y qué cosa mantenía el balance y el orden en esta colectividad humana que no invocaba ni toleraba siquiera la intervención del gobierno político? [...] El paradigma de las cabras y los perros parecía ofrecer una respuesta. La naturaleza biológica del hombre aparecía como el fundamento dado de una sociedad que no era de orden político. Fue así que los economistas renunciaron pronto a los fundamentos humanistas de Adam Smith e incorporaron los de Townsend. La ley de la población de Malthus y la ley de los rendimientos decrecientes manejada por Ricardo, hacían de la fecundidad del hombre y del suelo elementos constitutivos del nuevo reino cuya existencia había sido puesta al descubierto. La sociedad económica había surgido como algo distinto del Estado político"32. Esa nueva realidad que había emergido ante la conciencia científica y ante el imaginario común, la realidad de lo social, lo había hecho bajo la forma de un sistema económico cuyo funcionamiento se había desprendido y separado de todo tejido institucional y comunitario para erigirse en un mecanismo autónomo regido por sus propias leyes y determinaciones, que por cierto eran ingobernables y absolutas, no cabiendo antes ellas nada más que la adaptación, pero nunca la modificación. Porque, en definitiva, las leyes económicas constituían el espacio natural al que había que adaptarse o perecer.

Esa esfera económica, por lo tanto, que se había ido independizando de toda estructura política o social previa había de encontrar un fundamento más allá de los límites del orden moral y político; y ese más allá, de la mano del naturalismo, había terminado siendo la inmanencia de la vida biológica. "Las circunstancias bajo las cuales se hizo evidente la existencia de este agregado humano -una sociedad compleja- eran sumamente importantes para la historia del pensamiento del siglo XIX. Dado que la sociedad emergente no era otra cosa que el sistema de mercado, la sociedad humana estaba ahora en peligro de ser colocada sobre cimientos totalmente extraños al mundo moral del que el cuerpo político había formado parte hasta ahora" 33 . La nueva realidad de lo económico se asimilaba a una desnuda realidad natural, esto es, a-política. Cualquier orden político ajeno al funcionamiento de los mercados liberados quedaba desautorizado por tratar de contravenir el despliegue de un orden cuya legalidad había de funcionar a través de una dinámica inmodificable y autónoma.

La disertación contra la Ley de Pobres de Townsend venía a consignar semejante proceso, como hemos visto, y el joven Marx daba cuenta del mismo fenómeno. Creemos importante insertar aquí un pasaje crudamente sarcástico de Karl Polanyi en el que casi amargamente relata las consecuencias brutales de estas prácticas sociales y teóricas. “Por qué habría de convertirse a los pobres en una carga pública, encomendando su mantenimiento a la parro-

32 Ibíd.,p. 169.

33 Ibíd., p. 170.

Daimon. Revista Internacional de Filosofía, nº 69, 2016 
quia, si en última instancia la parroquia cumplía su obligación entregando a quienes podían trabajar a los empresarios capitalistas, quienes estaban tan ávidos por llenar sus fábricas con ellos que estarían dispuestos incluso a pagar dinero por obtener sus servicios? ¿No indicaba esto claramente que había también una forma menos cara de obligar a los pobres a ganarse el sustento, en lugar de recurrir a la parroquia? La solución se encontraba en la abolición de la legislación isabelina sin reemplazarla por ninguna otra. Que no se subsidiaran los salarios, ni se ayudara a los desempleados que pudieran trabajar, pero que tampoco hubiera salarios mínimos ni una salvaguardia del derecho a vivir. Debería tratarse a los trabajadores como lo que eran: una mercancía que debe encontrar su precio en el mercado. Las leyes del comercio eran las leyes de la naturaleza y en consecuencia las leyes de Dios. ¿Qué era esto sino una apelación del magistrado más débil al más fuerte, del juez de paz a los omnipotentes dolores del hambre? Para el político y el administrador, el laissez-faire era simplemente un principio del aseguramiento de la ley y el orden, con el mínimo de costo y esfuerzo. Que el mercado se encargue de los pobres, y las cosas se arreglarán por sí solas. Fue en este punto que Bentham, el racionalista, convenía con Burke, el tradicionalista. El cálculo del dolor y el placer requería que no se infligiera ningún dolor evitable. Si el hambre realizaba la tarea, no se requería ningún otro castigo [...] La pobreza era la naturaleza que sobrevivía en la sociedad; su sanción física era el hambre" ${ }^{34}$. Cita Polanyi, en efecto, a uno de los insignes y conspicuos padres de esta nueva economía política, paladín de la filosofía moral y social utilitarista. Decía, en efecto, Jeremy Bentham en su Principles of Civil Code: "Si la fuerza de la sanción física es suficiente, el empleo de la sanción política será superfluo"35. No se podía expresar de una manera más diáfana, desde luego.

Ya en Turgot estaba anticipada la "ley de hierro de los salarios", por la cual aquellos obreros que no tenían otra propiedad para vender más que la "industria de sus brazos" estaban condenados a permanecer en el límite mismo de la subsistencia física, ya que un obrero con su salario "sólo gana su vida" ${ }^{36}$. David Ricardo, de igual modo, también observaría en Principles of Political Economy and Taxation que el "precio natural" del trabajo es aquél que permite obtener al trabajador lo suficiente para subsistir, y establece lo siguiente: "El precio de mercado de la mano de obra es el que se paga realmente por ella, debido al funcionamiento natural de la ley de la oferta y la demanda; la mano de obra es cara cuando es escasa, y barata cuando es abundante. Por mucho que pueda su precio de mercado desviarse del natural, tiene, lo mismo que las mercancías, cierta tendencia a ajustarse a éste" ${ }^{37}$. En efecto, aunque de una manera coyuntural el precio de la mano de obra pudiera situarse por encima de ese "precio natural", ello duraría relativamente poco tiempo ya que en ese caso el trabajador dispondría de más recursos para mantener una familia más numerosa y esto redundaría en un incremento demográfico general que provocaría, a continuación, un incremento de oferta de trabajo que, a su vez, haría descender de nuevo el precio de la mano de obra, volviendo de nuevo al límite "natural" de la mera subsistencia. "En el progreso natural de la sociedad, los salarios tendrán una tendencia a bajar, en cuanto son regulados por la oferta y

34 Ibíd.

35 Ibíd.

36 Turgot, A. R. J., Reflexiones sobre la formación y la distribución de las riquezas. Elogio de Gournay, Madrid, Unión Editorial, 2009, p. 45.

37 Ricardo, D., Principios de economía política, Madrid, Sarpe, 1985, p. 88. 
la demanda, pues la oferta de mano de obra seguirá aumentando al mismo tipo, mientras la demanda aumentará a un tipo menor" ${ }^{38}$. Esta "ley de hierro de los salarios" es tomada, y así lo asevera Ricardo abiertamente, de "la hábil pluma de Mr. Malthus", el cual nunca cejó en su empeño de construir un armazón teórico dentro del cual el "orden natural de las cosas" implicaba que la mayoría de la población trabajadora habría de vivir en los límites mismos de la escasez, que era tomada como un inquebrantable límite no tanto institucional-político como biocenótico-ecológico ${ }^{39}$.

Dada una desigualdad, presuntamente irreductible, entre el ritmo de crecimiento de la población y la productividad agrícola y manufactura se generaban necesariamente unos efectos que apenas pueden ser mitigados por ninguna intervención humana. "No veo manera por la que el hombre pueda eludir el peso de esta ley, que abarca y penetra toda la naturaleza humana. Ninguna pretendida igualdad, ninguna reglamentación agraria, por muy radical que sea, podrá eliminar, durante un siglo siquiera, la presión de esta ley [...]" ${ }^{40}$. Dentro del naturalismo de Malthus, del que beben Ricardo y todos los economistas liberales clásicos, ese orden implacable no puede ser subvertido de ninguna manera, no al menos de una forma permanente.

Las fuerzas que regulan la oferta y la demanda en el mercado de mano de obra nunca pueden ser interrumpidas por demasiado tiempo, y si los salarios son incrementados de manera "anti-natural" a través, por ejemplo, de una ley de salario mínimo, la población obrera podrá procrear más y este incremento de la masa proletaria provocará a su vez el subsecuente abaratamiento del precio del trabajo debido al incremento de la oferta del mismo. En este constructo teórico que estamos dibujando las leyes demográficas, la escasez de medios de subsistencia y el mecanismo del mercado de trabajo constituyen un mismo orden natural inexorable. Concluye Malthus en su ensayo: "[...] sobre una parte de la sociedad deben necesariamente recaer las dificultades de la vida, y éstas recaen, por ley natural, sobre sus miembros menos afortunados" 4 .

A la luz de todo lo cual podemos sostener de una manera fundada que existió un fuerte naturalismo que permeó con notable incidencia el pensamiento social y económico del siglo XIX y que ha permanecido latiendo aún durante mucho tiempo dentro de los discursos de buena parte de los apologetas del sistema de libre mercado.

\section{Darwinismo social y sociedad darwiniana}

El traslado a la vida social de los imperativos biológicos es absolutamente evidente, en efecto, en el más clásico de los darwinistas sociales, Herbert Spencer. "El mandamiento «comerás el pan con el sudor de tu frente» es sencillamente una enunciación cristiana de una ley universal de la Naturaleza, y a la que debe la vida su progreso. Por esta ley, una criatura incapaz de bastarse a sí misma debe perecer [...]"42 Los débiles han de perecer en la lucha por la existencia, y no se debe tratar de remediar lo que es fruto de la necesidad natural. El

38 Ibíd., p. 93.

39 Collantes, F., "Robert Malthus: un economista político convertido en demógrafo por aclamación popular", Reis, $\mathrm{N}^{\mathrm{o}}$ 101, Universidad de Zaragoza. 2003.

40 Malthus, R., Primer ensayo sobre la población, Madrid, Alianza, 1970, p. 55.

41 Ibíd.p. 92.

42 Spencer, H., El hombre contra el Estado, Buenos Aires, Aguilar, 1963, p. 50. 
hambre, la enfermedad, la miseria, son el resultado de la brega natural por la supervivencia, y aquéllos que no pueden subsistir no han de ser artificialmente auxiliados por legislación social alguna. La naturaleza, que aparece identificada con el mercado, emite su dictado y no ha de ser contravenida.

En ese sentido sí cabe hablar de "ideologías científicas", a pesar del aparente oxímoron que tal expresión denota. Y, como bien señalaba Canguilhem, uno de los mejores ejemplos es, precisamente, el evolucionismo sistematizado y propugnado por Herbert Spencer, que cumplió de manera evidente una función legitimadora del sistema económico de libre empresa y del individualismo competitivo. "Si hay extensión a la totalidad de la experiencia humana, y sobre todo a la experiencia social, de conclusiones teóricas regionales desprendidas de sus premisas y liberadas de su contexto, ¿con qué fin se persigue este contagio de cientificidad? Con un fin práctico. La ideología evolucionista funciona como autojustificación de los intereses de un tipo determinado de sociedad, la sociedad industrial" ${ }^{43}$. No cabe aseverar, obviamente, que el evolucionismo del siglo XIX se reducía a ideologías como la spenceriana. Pero la defensa apologética del laissez-faire, en ese sentido, se sintió muy cómoda en el interior de una concepción naturalizada de la sociedad humana.

Alexander Tille, otro intelectual orgánico de la gran industria que, por cierto, había realizado la primera traducción al inglés de Nietzsche, entendía que las políticas sociales o sanitarias ejercidas por parte de un Estado humanitario devenían medidas contraproducentes en el largo plazo, precisamente en tanto en cuanto dichas medidas suponían un sostenimiento contranatural de los elementos más débiles de la sociedad humana y un consecuente debilitamiento del cuerpo social ${ }^{44}$. En este universo discursivo, por lo tanto, "privilegio de clase" y "aristocracia biológica" aparecían como términos semánticamente fusionados. El punto álgido de este darwinismo social se alcanzaría sin duda en la obra de William Graham Summer ${ }^{45}$.

En esa sociedad animalizada se entabla una permanente lucha biológica en la que no cabe ningún tipo de conmiseración. Los débiles no han de ser salvaguardados, so pena de quebrantar las leyes de la vida. "En el hombre, como en los animales inferiores, la conservación de la especie se asegura por la ley en virtud de la cual los individuos adultos más aptos, según las condiciones de la existencia que le son propias, son también los que prosperan más, mientras que los individuos menos adaptados son los que prosperan menos. Esta ley, cuando ningún obstáculo la estorba, produce la supervivencia de los más aptos y la expansión de las variedades mejor dotadas" 46 . Se trata de una sociedad humana animalizada de tal modo que la única política posible es la que no existe, un "dejar hacer" a la espontánea competencia natural de individuos reducidos a su condición biológica. Una sociedad animalizada que es, no lo perdamos de vista, una sociedad ampliamente mercantilizada.

43 Canguilhem, G., Ideología y racionalidad en la historia de las ciencias de la vida, Buenos Aires, Amorrortu, 2005 , p. 55.

44 Mocek, R., Socialismo revolucionario y darwinismo social, Madrid, Akal, 1999, p. 17.

45 Summer, W. G., Social Darwinism. Selected essays of William Graham Summer, New Jersey, Prentice-Hall, Englewood Cliffs, 1963.

46 Spencer, H., La justicia, Madrid, La España Moderna, p. 24. 
George Dalton, discípulo de Karl Polanyi, también señalaba ese naturalismo que penetró en la médula teórica de la economía política liberal, y sus palabras nos sirven de compilación de lo dicho hasta ahora. "Herbert Spencer y otros autores llegaron incluso a equiparar las fuerzas del mercado competitivo de oferta y demanda, con las fuerzas biológicas de Darwin para la selección natural: la competencia en el mercado era también la supervivencia del más fuerte. Esta conexión -«El Darwinismo Social»- no es accidental. Los economistas del siglo pasado también dedujeron sus leyes de hierro sobre las participaciones en la renta y la formación del precio a partir de lo que ellos consideraban la naturaleza ineluctable del hombre y de la tierra" ${ }^{47}$. Es así que el naturalismo, y esta es la principal conclusión que presentamos en este trabajo, se introduce en la médula de muchas de las explicaciones que se ofrecen de los fenómenos sociales de la pobreza y la riqueza. “Ahora se revelaba la verdadera significación del torturante problema de la pobreza: la sociedad económica estaba sujeta a leyes que no eran leyes humanas. La escisión entre Adam Smith y Townsend se había convertido en un abismo; apareció una dicotomía que marcaba el nacimiento de la conciencia del siglo XIX. A partir de este momento, el naturalismo persiguió al hombre de ciencia" ${ }^{48}$. La sociedad enteramente mercantilizada es una sociedad biologizada y naturalizada.

La competencia vital depura los elementos más débiles de la especie, pues la sociedad no ha de estar presidida más que por la ley que se expresa en la supervivencia del más apto. "Existe, en primer término, la innegable verdad, evidente y sin embargo ignorada, de que todos los fenómenos sociales tienen su origen en los fenómenos de la vida individual humana cuya raíz, a su vez, se encuentra en los fenómenos vitales en general"49. En el lenguaje de Spencer el término "vital" se refiere sin lugar a dudas a una noción desnudamente biológica de la vida. En este texto se trasluce nítidamente ese fenómeno que Hannah Arendt describiera como la invasión de la polis por la zoe, esto es, la ocupación del espacio político por los imperativos de la vida animal; un fenómeno no exento de execrables y peligrosas consecuencias. "Nada, en mi opinión, podría ser teóricamente más peligroso que la tradición de pensamiento orgánico en cuestiones políticas, por la que el poder y la violencia son interpretados en términos biológicos" ${ }^{50}$. Las condiciones de un capitalismo altamente competitivo coinciden, pues, con la textura de una sociedad naturalizada y animalizada. Tal vez, como concluía Arendt en otro lugar, "el hombre desee y esté a punto de evolucionar en esa especie animal de la que, desde Darwin, imagina que procede" ${ }^{1}$. Cuando la esfera de los asuntos humanos queda animalizada, cuando pretendemos comprender la praxis humana desde parámetros biologicistas, la acción política se reduce a pura lucha vital, a mera supervivencia animal, con todas las graves consecuencias que ello conlleva. Y lo que, en todo caso, fue un origen remoto puede transformase en ominoso destino inminente.

En 1926, en su The end of laissez-faire, Keynes incidía exactamente en la problemática que hemos venido esbozando a lo largo de estas páginas. Después de insistir en el

47 Dalton, G., Sistemas económicos y sociedad, Madrid, Alianza, 1974, p. 49.

48 Polanyi, K., La gran transformación, p. 180.

49 Spencer, H., El hombre contra el Estado, p. 137.

50 Arendt, H., Sobre la violencia, Madrid, Alianza, 2005, p. 101.

51 Arendt, H., La condición humana, Barcelona, Paidós, 2005, p. 339. 
hecho de que la doctrina del laissez-faire había configurado los marcos intelectuales y el sentido común de toda una época, Keynes muestra la textura naturalista que latía debajo de dichas concepciones. "Los economistas estaban enseñando que la riqueza, el comercio y la maquinaria eran las criaturas de la libre competencia y que la libre competencia hizo a Londres. Pero los darwinianos pudieron ir más lejos que eso: la libre competencia había hecho al hombre. El ojo humano ya no era la demostración del proyecto, $[\ldots]$ era el logro máximo de la casualidad, actuando en condiciones de libre competencia y laissez-faire. El principio de supervivencia del más apto podía considerarse como una amplia generalización de la economía ricardiana. Las interferencias socialistas venían a ser, a la luz de esta síntesis más completa, no sólo inconvenientes, sino sacrílegas, como calculadas para retrasar el movimiento progresivo del vigoroso proceso por medio del cual nosotros mismos habríamos salido como Afrodita del limo primitivo del océano" 52 . La ciencia económica, que estaba llamada a erigirse en la piedra angular de las ciencias sociales, se construyó a su vez como un discurso apologético y justificador de los terribles males sociales acarreados por los inéditos mecanismos institucionales que cristalizaron en la sociedad de mercado.

El proceso de naturalización que hemos venido desgranando en estas páginas ha de entenderse, empero, en dos sentidos muy distintos. Por un lado tenemos un proceso histórico real y dramático a través del cual las masas humanas, explotadas hasta la extenuación y desintegradas culturalmente, iban sumiéndose en unas condiciones de vida cada vez más ínfimas. Esas comunidades humanas, en el apogeo decimonónico de la sociedad industrial y de mercado, empezaban a sumergirse en el límite mismo de la mera subsistencia biológica. En ese sentido, también Polanyi podría afirmar que una sociedad de mercado cada vez más desarrollada constituía un modo de animalizar a las poblaciones humanas, obligadas a vivir en un entorno cada vez más degradado y teniendo que gastar casi todo el tiempo de vida en sufragar necesidades elementales, en medio de la fatiga inacabable del trabajo y la mortificación corporal y espiritual de una vida bestial.

Pero hemos de tener cuidado, porque una cosa es afirmar lo anterior, y esbozar una crítica de los efectos corrosivos de la industrialización capitalista sobre las vidas de las gentes comunes, y otra muy distinta introducir nociones y analogías naturalistas en los sistemas teóricos que tratan de explicar la realidad social, porque tal introducción sólo puede tener una finalidad apologética. Cuando los economistas burgueses hablaban de la "legalidad natural" de las leyes del mercado estaban tratando de obviar u ocultar que tal legalidad es histórico-cultural y, por ello mismo, contingente. Es cierto que dicho aparato institucional, el mecanismo del mercado, ha provocado una pavorosa animalización de las condiciones de vida de millones de seres humanos. Pero esta animalización es un proceso histórico-político que puede subvertirse, toda vez que es el efecto resultante de una determinada civilización histórica organizada por un entramado institucional muy concreto. Y sólo desde semejante comprensión, por cierto, podemos desactivar la ilusión que piensa las leyes del mercado capitalista como sempiternas condiciones de toda economía humana posible.

No está justificado entender que la "economía natural" de la humanidad haya de ser comprendida ineluctablemente como una descarnada lucha competitiva por la supervivencia, pues si tal ha terminado siendo ello se debe únicamente a una forma muy concreta de instituciona-

52 Keynes, J. M., Ensayos de persuasión, Barcelona, Crítica, 1988, p. 279. 
lizar la economía a través de un sistema de mercados libres. Otras formas de institucionalización económica son posibles, imaginables, concebibles y deseables, otras formas de integrar lo económico que no involucren a los hombres en una lucha competitiva y salvaje por unos recursos siempre escasos. Hablamos, en suma, de otra institucionalización de lo económico que no animalice las condiciones de vida de la gente común. En El origen de las especies, por lo tanto, no hallaremos el manual de economía política universal de la especie humana.

\section{Bibliografía citada}

Agamben, G., Lo abierto. El hombre y el animal, Valencia, Pre-textos, 2005.

Arendt, H., La condición humana, Barcelona, Paidós, 2005.

Arendt, H., Sobre la violencia, Madrid, Alianza, 2005.

Canguilhem, G., Ideología y racionalidad en la historia de las ciencias de la vida, Buenos Aires, Amorrortu, 2005.

Castel, R., Las metamorfosis de la cuestión social, Buenos Aires, Paidós, 1997.

Castrodeza, C., La darwinización del mundo, Barcelona, Herder, 2009.

Collantes, F., "Robert Malthus: un economista político convertido en demógrafo por aclamación popular", Reis, № 101, Universidad de Zaragoza. 2003.

Dalton, G., Sistemas económicos y sociedad, Madrid, Alianza, 1974.

Darwin, C., El origen del hombre y la selección en relación al sexo, Madrid, Ediciones Ibéricas, 1966.

Esposito, R., "Vida biológica y vida política", Pléyade, No 12, Julio-Diciembre 2013, pp. 15-33. Keynes, J. M., Ensayos de persuasión, Barcelona, Crítica, 1988.

Malthus, R., Primer ensayo sobre la población, Madrid, Alianza, 1970.

Marx, K., Manuscritos de economía y filosofía, Madrid, Alianza, 2010.

Mocek, R., Socialismo revolucionario y darwinismo social, Madrid, Akal, 1999.

Muñoz Rubio, J., "Biología y economía política: acerca del carácter interdisciplinario de la teoría de Darwin", en La interdisciplina y las grandes teorías del mundo moderno, Univesidad Nacional Autónoma de México, 2007.

Paine, T., El sentido común y otros escritos, Madrid, Tecnos, 1990.

Polanyi, K., La gran transformación, México, Fondo de Cultura Económica, 2003.

Ricardo, D., Principios de economía política, Madrid, Sarpe, 1985.

Sahlins, M., Uso y abuso de la biología, Madrid, Siglo Veintiuno, 1982.

Soutullo, D.; Biología, cultura y ética, Madrid, Talasa, 2005.

Spencer, H., La justicia, Madrid, La España Moderna, .

Spencer, H., El hombre contra el Estado, Buenos Aires, Aguilar, 1963.

Summer, W. G., Social Darwinism. Selected essays of William Graham Summer, New Jersey, Prentice-Hall, Englewood Cliffs, 1963.

Tinbergen, N., Hombre y animal. Estudios sobre comportamiento, Madrid, Hermann Blume, 1975.

Turgot, A. R. J., Reflexiones sobre la formación y la distribución de las riquezas. Elogio de Gournay, Madrid, Unión Editorial, 2009.

Wilson, E. O., Sociobiología. La nueva síntesis, Barcelona, Omega, 1980. 